\title{
Plot size related to numbers of treatments, repetitions, and the experimental precision in flax
}

\author{
Alberto Cargnelutti Filho*, Ismael Mario Márcio Neu, Gustavo Oliveira dos Santos, \\ Giovani Facco, Cleiton Antonio Wartha, Jéssica Andiara Kleinpaul
}

\begin{abstract}
The aim of this study was determining the optimum plot size to evaluate the fresh matter of aerial part in flax (Linum usitatissimum L.), in scenarios formed by combinations of numbers of treatments, number of repetitions, and precision levels. The fresh matter of aerial part was weighed on 144 basic experimental units of $1.00 \mathrm{~m}$ $\times 1.00 \mathrm{~m}$ in uniformity trial with size of $12 \mathrm{~m} \times 12 \mathrm{~m}\left(144 \mathrm{~m}^{2}\right)$. It was estimated the soil heterogeneity index of Smith (1938). Also, the optimum plot size was determined by the Hatheway's method (1961) in scenarios formed by combinations of $i$ treatments $(i=5,10,15$, and 20), r repetitions $(r=3,4,5,6,78,9$, and 10), and $d$ precision levels ( $d=10 \%, 12 \%, 14 \%, 16 \%, 18 \%, 20 \%, 22 \%, 24 \%, 26 \%, 28 \%, 30 \%, 32 \%, 34 \%, 36 \%, 38 \%$, and $40 \%$ ). In experiments planned on randomized block design, with 5 to 20 treatments and four repetitions, plots with 7 $\mathrm{m}^{2}$ are sufficient to identify significant differences between treatments regarding fresh matter of aerial part in flax, at $5 \%$ probability, of $34 \%$ of the experiment overall mean.
\end{abstract}

Keywords: experimental design, fresh matter of aerial part, Linum usitatissimum L., uniformity trial

\section{Introduction}

The flax (Linum usitatissimum L.) is an herbaceous plant of annual cycle, with common uses are textile fiber, oil for industry, feeding livestock (Floss, 1983), and for human consumption (Novello \& Pollonio, 2011). The potential of flax as a winter cover crop preceding the common beans (Rigon et al., 2011) and maize (Cherubin et al., 2014) has been investigated. The fresh matter of aerial part in cover crops, should be well dimensioned in order to have reliable results and accurate inferences. Thus, it is necessary to plan the experiment correctly and this planning can be performed based on data collected in uniformity trials.
The Hatheway's method (1961) has been used in studies of optimum plot size (Xo) for traits of wheat (Lorentz et al., 2007), sorghum (Brum et al., 2008), banana (Donato et al., 2008), zucchini (Feijó et al., 2008), strawberry (Cocco et al., 2009), chili pepper (Lorentz \& Lúcio, 2009), sunflower (Lorentz et al., 2010), lettuce (Lúcio et al., 2011), tomato (Lúcio et al., 2012) and green common bean (Santos et al., 2012). Initially, in approaches these studies, it was determined the soil heterogeneity index (b) of Smith (1938), followed by the use of different methodologies aiming to determine the Xo. Further, the Hatheway's method (1961) was used to determine the experimental precision, based on estimates of $\mathrm{b}$ and $\mathrm{Xo}_{\mathrm{O}}$, in scenarios formed by 
combinations of experimental designs, coefficients of variation, numbers of treatments and repetitions.

Alternatively, it is possible to estimate the coefficient of variation (CV) among basic experimental units and the soil heterogeneity index (b) of Smith (1938). Thereafter, use the Hatheway's method (1961) with the aim of determining the Xo according to the experimental design, number of treatments, number of repetitions, and desired precision. This approach, with different plot size estimates has advantages over the previous one, which has a unique optimum plot size. In the second approach, once the experimental design and the number of treatments to be evaluated are established, the researcher can choose the best combination of plot size, number of repetitions, and experimental precision levels. This approach has been used for traits in crops such as cassava (Viana et al., 2003), maize (Alves \& Seraphin, 2004), wheat (Henriques Neto et al., 2004), and bean (MayorDurán et al., 2012).

Furthermore, the second approach has also been used in the evaluation of fresh matter in species with potential as soil cover crops, such as velvet bean (Cargnelutti Filho et al., 2014a) and turnip (Cargnelutti Filho et al., 2014b). The aim of this study was determining the optimum plot size to evaluate the fresh matter of aerial part in flax, in scenarios formed by combinations of numbers of treatments, number of repetitions, and precision levels.

\section{Materials and Methods}

An uniformity trial (experiment without treatments, which the crop and all procedures performed during the experiment are homogeneous in the experimental area) was conducted with flax (Linum usitatissimum L.), cultivar CDC Normandy, in experimental area of $15 \mathrm{~m} \times 15 \mathrm{~m}\left(225 \mathrm{~m}^{2}\right)$ located in southern Brazil at $29^{\circ} 42^{\prime} \mathrm{S}, 53^{\circ} 49^{\prime} \mathrm{W}$, with $95 \mathrm{~m}$ altitude. According to Köppen climate classification, the climate is Cfa, subtropical humid, with warm summers and without dry season defined (Heldwein et al., 2009). A basic fertilization of $8 \mathrm{~kg} \mathrm{ha}^{-1} \mathrm{~N}, 80$ $\mathrm{kg} \mathrm{ha}^{-1}$ of $\mathrm{P}_{2} \mathrm{O}_{5^{\prime}}$ and $80 \mathrm{~kg} \mathrm{ha}^{-1}$ of $\mathrm{K}_{2} \mathrm{O}$ (only NPK in proportion 02-20-20) was carried out on June 13,2013 . Moreover, a procedure of broadcasting utilizing seeds in the density of $80 \mathrm{~kg} \mathrm{ha}^{-1}$ was done in that same day. As recommended for uniformity trials by Storck et al. (2011), the cultural practices were carried out homogeneously in the experimental area.

In the uniformity trial, the central area of size $12 \mathrm{~m} \times 12 \mathrm{~m}\left(144 \mathrm{~m}^{2}\right)$ was divided into 144 basic experimental units (BEU) of $1.00 \mathrm{~m} \times 1.00$ $\mathrm{m}$ forming a matrix with 12 rows and 12 columns. In each BEU of $1.00 \mathrm{~m}^{2}$, the plants were cut at the soil surface on October 11, 2013 (120 days after sowing), in the initial stage of grain filling. Hereafter, the fresh matter of aerial part (FM) was obtained by weighing in $\mathrm{g} \mathrm{m}^{-2}$. The number of plants was counted in six plots of $0.5 \mathrm{~m} \times 0.5$ $\mathrm{m}\left(0.25 \mathrm{~m}^{2}\right)$. The plots were taken randomly in the experimental area and the plant density obtained was 6,593,333 plants $\mathrm{ha}^{-1}$.

Minimum and maximum air temperatures in ${ }^{\circ} \mathrm{C}$ and rainfall in $\mathrm{mm}$ were recorded daily between sowing date (June 13, 2013) and the evaluation of FM (October 11, 2013). Those information were collected at the Automatic Experimental Station of the Federal University of Santa Maria, located $30 \mathrm{~m}$ away from the experimental area. The average daily air temperature, in ${ }^{\circ} \mathrm{C}$, was calculated as the arithmetic mean of the minimum and maximum air temperatures.

Plots with $X_{R}$ adjacent $B E U$ in the row and $X_{C}$ adjacent BEU in the column were designed based on FM data of 144 basic experimental units. The plots with different sizes and/or shapes were designed as $\left(X=X_{R} \times X_{C}\right)$, i.e., $(1 \times 1),(1 \times 2),(1 \times 3),(1 \times 4),(1 \times 6),(2 \times 1)$, $(2 \times 2),(2 \times 3),(2 \times 4),(2 \times 6),(3 \times 1),(3 \times 2),(3 \times 3),(3 \times 4)$, $(3 \times 6),(4 \times 1),(4 \times 2),(4 \times 3),(4 \times 4),(4 \times 6),(6 \times 1),(6 \times 2)$, $(6 \times 3),(6 \times 4)$, and $(6 \times 6)$. The abbreviations $X_{R^{\prime}} X_{C}$ and $X$ represent, respectively, number of adjacent $B E U$ in the row, number of adjacent BEU in the column and plot size in number of BEU.

Hereafter, for each plot size $(X)$, it was determined: $n$ - number of plots with $X$ BEU of size $(n=144 / X), M_{(X)}-$ mean of plots with $X$ BEU of size (in $\left.\mathrm{g} \mathrm{m}^{-2}\right), V_{(X)}$ - variance between plots with $X$ BEU of size, $\mathrm{CV}_{(\mathrm{X})}$ - coefficient of variation (in percentage) between plots with $X \mathrm{BEU}$ of size, and $\mathrm{VU} \mathrm{U}_{(\mathrm{X})}$ - variance by BEU between plots with $X$ BEU of size $\left[V U_{(X)}=V_{(X)} / X^{2}\right]$. Subsequently, two parameters were estimated: V1 (estimate of variance by BEU between plots with one BEU size) and b (estimate of soil heterogeneity index), and coefficient of 
determination $\left(\mathrm{r}^{2}\right)$ of the function $\mathrm{VU}(\mathrm{X})=\mathrm{V} 1 / \mathrm{X}^{\mathrm{b}}$ of Smith (1938). These parameters were estimated by logarithmic transformation, and consequently the linearization of the function $V U_{(x)}=V 1 / X^{b}$ (Smith, 1938), i.e., $\log V U_{(X)}=\log V 1-b \log X$, whose estimation is weighed by the degrees of freedom (DF=n-1) associated to each plot sizes. The observed values of the dependent $[\mathrm{VU}(\mathrm{x})]$ and independent $(X)$ variables and the function $\mathrm{VU}_{(\mathrm{x})}=\mathrm{V} 1 / \mathrm{X}^{\mathrm{b}}$ (Smith 1938) were plotted.

Experimental designs were simulated in a randomized block design (commonly used in field experiments) for scenarios formed by combinations of $i$ treatments $(i=5,10,15$, and $20)$, r repetitions $(r=3,4,5,6,7,8,9$, and 10$)$ and $d$ differences between treatment means detected as significant at the $5 \%$ probability, expressed as a percentage of mean, i.e., different precision levels $(d=10 \%, 12 \%, 14 \%, 16 \%, 18 \%, 20 \%, 22 \%$, $24 \%, 26 \%, 28 \%, 30 \%, 32 \%, 34 \%, 36 \%, 38 \%$, and $40 \%)$. In this case $d=10 \%$ indicates more precision and in the meantime, the other extreme $d=40 \%$, indicates smaller precision.

The optimum plot size (Xo) was calculated for each experimental design, in number of BEU (rounded to the integer greater number) by using the expression $x_{0}=\sqrt[b]{2\left(t_{1}+t_{2}\right)^{2} \mathrm{CV}^{2} / r d^{2}}$ (Hatheway 1961). In this expression, $b$ is the estimate of soil heterogeneity index; $t_{1}$ is the critical value of Student's $t$ distribution for the significance level of the test (type lerror) of $a=5 \%$ (5\% of two-tailed test) with DF degrees of freedom; $t_{2}$ is the critical value of the Student's $†$ distribution, corresponding to 2(1-P) (two-tailed test), where $P$ is the probability of obtaining significant result, i.e., the test power ( $P=0.80$, in this study), with DF degrees of freedom; $\mathrm{CV}$ is the estimate of the coefficient of variation between plots of one BEU size, in percentage; $r$ is the number of repetitions; and $d$ is the difference between treatment means detected as significant at the $5 \%$ probability, expressed as a percentage of the overall mean of the experiment (precision). The degrees of freedom (DF) to obtain the critical values (tabulated) of the Student's $\uparrow$ distribution were obtained by the expression $D F=(i-1)(r-1)$, where $i$ is the number of treatments and $r$ is the number of repetitions. In this study, the value of $t_{1}$ and $t_{2}$ were obtained with Microsoft Office Excel® application, through the functions $t_{1}=\operatorname{INVT}(0.05 ; \mathrm{DF})$ and $t_{2}=\operatorname{INVT}(0.40 ; \mathrm{DF})$, respectively. Statistical analyzes were performed using Microsoft Office Excel® application.

\section{Results and Discussion}

In 25 designed plots with different sizes and/or shapes, regarding to the fresh matter of aerial part (FM) of flax (Linum usitatissimum L.) cultivar CDC Normandy, there was increase in the mean of plots $\left[M_{(x)}\right]$ and variance among the plots $\left[V_{(x)}\right]$ and decrease in the coefficient of variation $\left[\mathrm{CV}_{(\mathrm{x})}\right]$ and variance by BEU among plots $\left[\mathrm{VU} \mathrm{(x)}_{(\mathrm{x})}\right]$, with an increase in the designed plot size $(X)$ ( Table 1). In the area where 144 basic experimental units (BEU) of $1.00 \mathrm{~m}^{2}$ were evaluated, the FM average ranged from 6,110 $\mathrm{kg} \mathrm{ha}^{-1}$ to $22,800 \mathrm{~kg} \mathrm{ha}^{-1}$ and the average was $11,295.6 \mathrm{~kg} \mathrm{ha}^{-1}$ (Table 1). Moreover, similar value of $11,530 \mathrm{~kg} \mathrm{ha}^{-1}$ was obtained by Cherubin et al. (2014). Thus, the FM of $11,295.6 \mathrm{~kg} \mathrm{ha}^{-1}$ suggests adequate an growth and development of flax in the local environmental conditions (Figure 1). Furthermore, it reveals the importance of continuing studies on the feasibility of flax use as a cover crop species, as already performed by Rigon et al. (2011) and Cherubin et al. (2014).

The coefficient of variation (CV) of fresh matter of aerial part between $144 \mathrm{BEU}$ of $1.00 \mathrm{~m}^{2}$ was $23.60 \%$ (Table 1), similar to the CV of $21.78 \%$ observed in the evaluation of fresh matter of aerial part in velvet bean (Cargnelutti Filho et al., 2014a). Also, this value is similar to the $\mathrm{CV}$ of $22.92 \%$ obtained by Cherubin et al. (2014) in evaluation of the fresh matter of linseed and other cover crops predecessors of corn. The variability among the 144 BEU where the FM was evaluated has importance for the study of the optimum plot size. This variability reflects real field conditions areas. Therefore, proper growth and development of flax plants and the wide variability between BEU provide credibility to this database for the proposed study.

The soil heterogeneity index (b) of Smith's function (1938) was 0.4269. Alves \& Seraphin (2004) argues that in the expression of Hatheway (1961), the parameter $b$ interferes differently in the Xo estimation. Moving forward this discussion, it is observed that when the result of $\left\{2\left(t_{1}+t_{2}\right)^{2} \mathrm{CV}^{2} / \mathrm{rd}^{2}\right\}$ is smaller than one, the greater the $b$ value, the greater the Xo estimated, but Xo will always be smaller 
than one BEU. However, when $\left\{2\left(t_{1}+t_{2}\right)^{2} \mathrm{CV}^{2} / r \mathrm{~d}^{2}\right\}$ is $\left\{2\left(t_{1}+t_{2}\right)^{2} \mathrm{CV}^{2} / \mathrm{rd}^{2}\right\}$ is equal to one, $\mathrm{XO}$ is always equal to greater than one, the higher $b$, the lower $X_{0}$, but one BEU, regardless of $b$.

Xo will always be greater than one BEU. Also, when

Table 1. Designed plot size $\left(X=X_{R} \times X_{C}\right)$, in basic experimental units (BEU), with $X_{R}$ adjacent $B E U$ in the row and $X_{C}$ adjacent $B E U$ in the column; number of plots with $X$ BEU of size $(n=144 / X)$; mean of plots with $X$ BEU of size [ $\left.M_{(X)}\right]$, in grams; variance between plots with $X$ BEU of size $\left[V_{(x)}\right]$; coefficient of variation (in percentage) between plots with $X$ BEU of size $\left[\mathrm{CV}_{(x)}\right]$; and, variance by BEU between plots with $X \mathrm{BEU}$ of size $\left[\mathrm{VU} U_{(X)}=V_{(X)} / X^{2}\right]$. Fresh matter of aerial part data in flax (Linum usitatissimum L.), cultivar CDC Normandy, in an uniformity trial with 144 BEU of 1.00 m² $^{2}$

\begin{tabular}{cccccccc}
\hline $\mathrm{X}_{\mathrm{R}}$ & $\mathrm{X}_{\mathrm{C}}$ & $\mathrm{X}$ & $\mathrm{n}$ & $\mathrm{M}_{(\mathrm{x})}$ & $\mathrm{V}_{(\mathrm{x})}$ & $\mathrm{CV}_{(\mathrm{x})}$ & $\mathrm{VU}_{(\mathrm{x})}$ \\
\hline 1 & 1 & 1 & 144 & $1,129.56$ & $71,055.76$ & 23.60 & $71,055.76$ \\
1 & 2 & 2 & 72 & $2,259.11$ & $210,540.72$ & 20.31 & $52,635.18$ \\
1 & 3 & 3 & 48 & $3,388.67$ & $395,491.93$ & 18.56 & $43,943.55$ \\
1 & 4 & 4 & 36 & $4,518.22$ & $561,586.69$ & 16.59 & $35,099.17$ \\
1 & 6 & 6 & 24 & $6,777.33$ & $870,698.75$ & 13.77 & $24,186.08$ \\
2 & 1 & 2 & 72 & $2,259.11$ & $202,011.54$ & 19.90 & $50,502.88$ \\
2 & 2 & 4 & 36 & $4,518.22$ & $583,510.01$ & 16.91 & $36,469.38$ \\
2 & 3 & 6 & 24 & $6,777.33$ & $1,158,906.49$ & 15.88 & $32,191.85$ \\
2 & 4 & 8 & 18 & $9,036.44$ & $1,717,712.26$ & 14.50 & $26,839.25$ \\
2 & 6 & 12 & 12 & $13,554.67$ & $2,134,396.97$ & 10.78 & $14,822.20$ \\
3 & 1 & 3 & 48 & $3,388.67$ & $447,454.52$ & 19.74 & $49,717.17$ \\
3 & 2 & 6 & 24 & $6,777.33$ & $1,303,064.06$ & 16.84 & $36,196.22$ \\
3 & 3 & 9 & 16 & $10,166.00$ & $2,654,457.07$ & 16.03 & $32,771.07$ \\
3 & 4 & 12 & 12 & $13,554.67$ & $3,852,659.33$ & 14.48 & $26,754.58$ \\
3 & 6 & 18 & 8 & $20,332.00$ & $5,062,049.71$ & 11.07 & $15,623.61$ \\
4 & 1 & 4 & 36 & $4,518.22$ & $637,465.61$ & 17.67 & $39,841.60$ \\
4 & 2 & 8 & 18 & $9,036.44$ & $1,968,574.26$ & 15.53 & $30,758.97$ \\
4 & 3 & 12 & 12 & $13,554.67$ & $4,215,071.15$ & 15.15 & $29,271.33$ \\
4 & 4 & 16 & 9 & $18,072.89$ & $6,030,361.86$ & 13.59 & $23,556.10$ \\
4 & 6 & 24 & 6 & $27,109.33$ & $7,608,435.07$ & 10.17 & $13,209.09$ \\
6 & 1 & 6 & 24 & $6,777.33$ & $1,383,518.93$ & 17.36 & $38,431.08$ \\
6 & 2 & 12 & 12 & $13,554.67$ & $4,320,752.79$ & 15.34 & $30,005.23$ \\
6 & 3 & 18 & 8 & $20,332.00$ & $9,095,842.29$ & 14.83 & $28,073.59$ \\
6 & 4 & 24 & 6 & $27,109.33$ & $14,433,146.27$ & 14.01 & $25,057.55$ \\
6 & 6 & 36 & 4 & $40,664.00$ & $17,102,678.00$ & 10.17 & $13,196.51$ \\
\hline
\end{tabular}

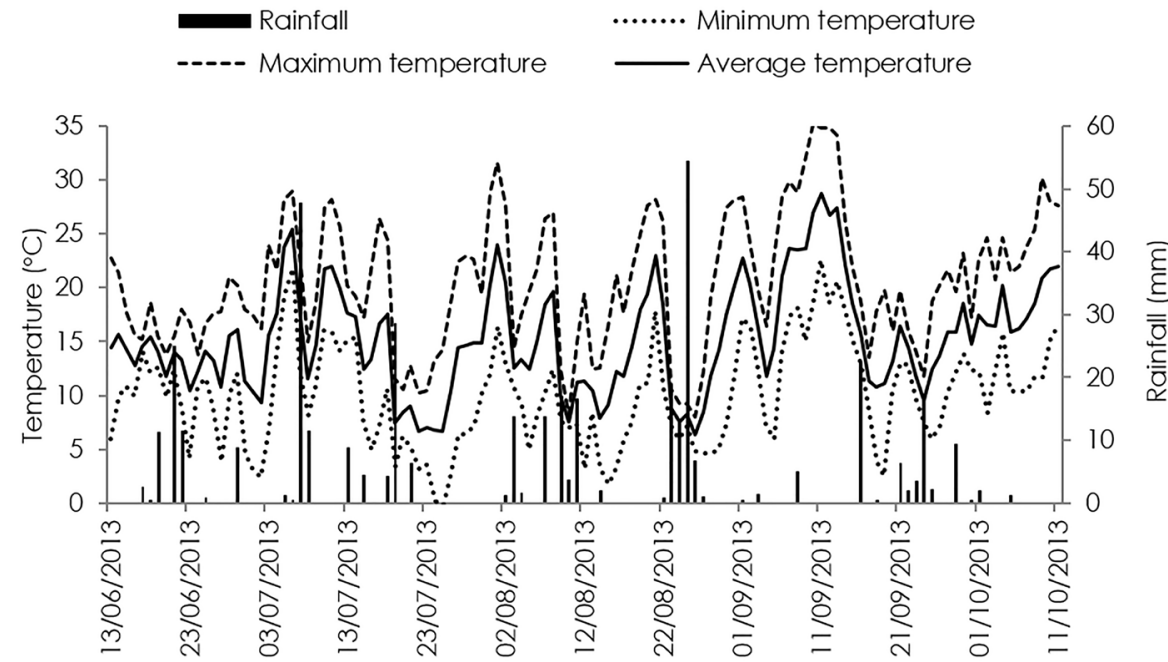

Figure 1. Minimun, maximum and average daily air temperatures in ${ }^{\circ} \mathrm{C}$ and rainfall in $\mathrm{mm}$, corresponding to the period in which the experiment was conducted with flax (Linum usitatissimum L.), cultivar CDC Normandy. Data from Automatic Experimental Station of the Federal University of Santa Maria (Source: INMET Network Data) 
Visually, it was observed pronounced decreases in variance by $\mathrm{BEU}\left[\mathrm{VU} \mathrm{V}_{(\mathrm{x})}\right]$ with plots of $\mathrm{up}$ to four BEU size $\left(4 \mathrm{~m}^{2}\right)$, intermediate between size of four to eight BEU, and a stabilization trend with plots larger than eight BEU (Figure 2 ). This behavior was similar to the observations in velvet bean (Cargnelutti
Filho et al., 2014a) and turnip (Cargnelutti Filho et al., $2014 \mathrm{~b})$. Therefore, to assess the fresh matter of aerial part of flax, the suggestion is a plot of up to eight BEU $\left(8 \mathrm{~m}^{2}\right)$ because the gain in experimental precision (decrease in $\mathrm{VU}_{(\mathrm{X})}$ ) with growing increases in plot size greater than eight BEU was inexpressive.

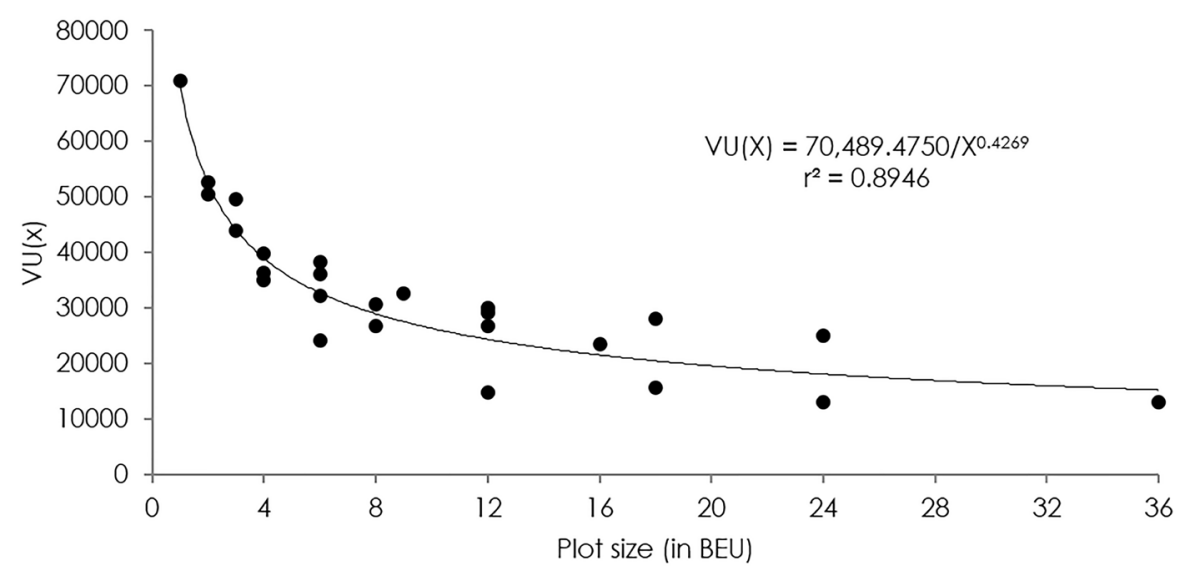

Figure 2. Graphical representation of the relation between the variance by basic experimental unit (BEU) between plots with $X \mathrm{BEU}$ size $\left[\mathrm{VU}\left(\mathrm{XX)}=\mathrm{V}_{(\mathrm{X})} / \mathrm{X}^{2}\right]\right.$ and the designed plot size $(\mathrm{X})$, in $\mathrm{BEU}$ and estimates of the function parameters $\mathrm{VU}(\mathrm{X})=\mathrm{V} 1 / \mathrm{X}^{\mathrm{b}}$ of Smith (1938). Fresh matter of aerial part data in flax (Linum usitatissimum L.), cultivar CDC Normandy, in an uniformity trial with $144 \mathrm{BEU}$ of $1.00 \mathrm{~m}^{2}$.

In experiment carried out in randomized block design, the optimum plot size (Xo) to evaluate the FM in flax, in BEU, estimated by Hatheway's method (1961), with a fixed number of treatments (i) and repetitions ( $r$ ) increases with increments in the desired precision (d) (Table 2). For instance, concerning to evaluate the FM in an experiment with five treatments ( $i=5)$ and three repetitions ( $r=3$ ), aiming that in $80 \%$ of experiments (power=0.80), differences between treatments of $d=40 \%$ of overall average of the experiment (lower precision) are found to be significant at the $5 \%$ probability with plot size of eight BEU $\left(8 \mathrm{~m}^{2}\right)$ (Table 2). This plot size is viable in field trials but the experimental precision is low. Thus, in these same conditions, at the other extreme, a plot with 4,988 BEU $\left(4,988 \mathrm{~m}^{2}\right)$ would be necessary supposing $d=10 \%$ (greater precision). In this situation the experimental precision is higher, but carry out a field experiment with plot size of $4,988 \mathrm{~m}^{2}$ is impracticable. Therefore, these results demonstrate that aimed high experimental precision (low percentages of d) are difficult to be achieved in practice due to the necessity of high plot size, as pointed out by Cargnelutti Filho et al. (2014a, b).

Optimum plot size (Xo) decreases with the increase in number of repetitions ( $r$ ) with fixed number of treatments (i) and precision (d). Furthermore, there is a reduction of the optimum plot size (Xo) with an increase in number of treatments (i) with fixed values of repetitions ( $r$ ) and precision (d) (Table 2). These results can be explained by the fact that the greater the number of treatments and the number of repetitions, the greater the number of degrees of freedom of error. Consequently, the estimate of the residual variance (mean square error) will be smaller, i.e., with higher experimental precision.

According to the methodology of Hatheway (1961), based on the fixed value of the soil heterogeneity index (b) of Smith (1938), the optimum plot size $(\mathrm{XO})$ is dependent on the number of treatments (i), the number of repetitions ( $r$ ), and precision (d). Thereby, the researcher can use the information provided by this study to plan the plot size and the number of repetitions based on the number of treatments and precision required. For example, if the researcher wants to evaluate the FM in ten treatments with required precision (d) of $30 \%$, between the various options, it can be used plots of $21 \mathrm{BEU}\left(21 \mathrm{~m}^{2}\right)$ and three repetitions, ten BEU (10 $\left.\mathrm{m}^{2}\right)$ and four repetitions, six BEU $\left(6 \mathrm{~m}^{2}\right)$ and five repetitions or four BEU $\left(4 \mathrm{~m}^{2}\right)$ and six repetitions (Table 2). In these four choices, the area of the experiment would be $630,400,300$, and $240 \mathrm{~m}^{2}$, respectively. Therefore, for 
the same precision ( $d=30 \%$, in this case), small plots and more repetitions are more efficient in the use of the experimental area, as discussed in Alves \& Seraphin (2004), Henriques Neto et al. (2004), Storck et al. (2011) and Cargnelutti Filho et al. (2014a, b). Moreover, it is important to consider that with an increase in number of repetitions more evaluations are required. Besides, if the trait is difficult to measure and/or costly to evaluate, the use of larger plot sizes and fewer repetitions can be advantageous whereas there is availability of experimental area. Therefore, the researcher must investigate within availability of experimental area, the number of treatments to be evaluated and the desired precision to find what combination of plot size and number of repetitions is the most appropriate.

Table 2. Optimal plot size (Xo) in basic experimental units of $1.00 \mathrm{~m}^{2}$, estimated by Hatheway's methodology (1961) for experimental design in a randomized block design, in scenarios formed by combinations of $\mathrm{i}$ treatments, $r$ repetitions and d differences between treatment means to be detected as significant at the $5 \%$ probability, expressed as a percentage of the experiment overall mean (precision) for fresh matter of aerial part data in flax (Linum usitatissimum L.), cultivar CDC Normandy

\begin{tabular}{|c|c|c|c|c|c|c|c|c|c|c|c|c|c|c|c|c|c|}
\hline \multirow[t]{2}{*}{ i } & \multirow[t]{2}{*}{$r$} & \multicolumn{16}{|c|}{$d(\%)$} \\
\hline & & 10 & 12 & 14 & 16 & 18 & 20 & 22 & 24 & 26 & 28 & 30 & 32 & 34 & 36 & 38 & 40 \\
\hline 5 & 3 & 4,988 & 2,123 & 1,032 & 552 & 318 & 194 & 125 & 83 & 57 & 41 & 30 & 22 & 17 & 13 & 10 & 8 \\
\hline 5 & 4 & 2,050 & 873 & 424 & 227 & 131 & 80 & 51 & 34 & 24 & 17 & 12 & 9 & 7 & 6 & 4 & 4 \\
\hline 5 & 5 & 1,096 & 467 & 227 & 122 & 70 & 43 & 28 & 19 & 13 & 9 & 7 & 5 & 4 & 3 & 3 & 2 \\
\hline 5 & 6 & 673 & 287 & 140 & 75 & 43 & 27 & 17 & 12 & 8 & 6 & 4 & 3 & 3 & 2 & 2 & 2 \\
\hline 5 & 7 & 451 & 192 & 94 & 50 & 29 & 18 & 12 & 8 & 6 & 4 & 3 & 2 & 2 & 2 & 1 & 1 \\
\hline 5 & 8 & 320 & 137 & 67 & 36 & 21 & 13 & 8 & 6 & 4 & 3 & 2 & 2 & 2 & 1 & 1 & 1 \\
\hline 5 & 9 & 238 & 102 & 50 & 27 & 16 & 10 & 6 & 4 & 3 & 2 & 2 & 2 & 1 & 1 & 1 & 1 \\
\hline 5 & 10 & 183 & 78 & 38 & 21 & 12 & 8 & 5 & 4 & 3 & 2 & 2 & 1 & 1 & 1 & 1 & 1 \\
\hline 10 & 3 & 3,504 & 1,492 & 725 & 388 & 224 & 137 & 88 & 58 & 40 & 29 & 21 & 16 & 12 & 9 & 7 & 6 \\
\hline 10 & 4 & 1,634 & 696 & 338 & 181 & 105 & 64 & 41 & 28 & 19 & 14 & 10 & 8 & 6 & 5 & 4 & 3 \\
\hline 10 & 5 & 927 & 395 & 192 & 103 & 60 & 37 & 24 & 16 & 11 & 8 & 6 & 4 & 3 & 3 & 2 & 2 \\
\hline 10 & 6 & 589 & 251 & 122 & 66 & 38 & 23 & 15 & 10 & 7 & 5 & 4 & 3 & 2 & 2 & 2 & 1 \\
\hline 10 & 7 & 404 & 172 & 84 & 45 & 26 & 16 & 11 & 7 & 5 & 4 & 3 & 2 & 2 & 1 & 1 & 1 \\
\hline 10 & 8 & 292 & 125 & 61 & 33 & 19 & 12 & 8 & 5 & 4 & 3 & 2 & 2 & 1 & 1 & 1 & 1 \\
\hline 10 & 9 & 220 & 94 & 46 & 25 & 14 & 9 & 6 & 4 & 3 & 2 & 2 & 1 & 1 & 1 & 1 & 1 \\
\hline 10 & 10 & 170 & 73 & 36 & 19 & 11 & 7 & 5 & 3 & 2 & 2 & 1 & 1 & 1 & 1 & 1 & 1 \\
\hline 15 & 3 & 3,185 & 1,356 & 659 & 353 & 203 & 124 & 80 & 53 & 37 & 26 & 19 & 14 & 11 & 8 & 7 & 5 \\
\hline 15 & 4 & 1,535 & 653 & 318 & 170 & 98 & 60 & 39 & 26 & 18 & 13 & 9 & 7 & 5 & 4 & 3 & 3 \\
\hline 15 & 5 & 885 & 377 & 183 & 98 & 57 & 35 & 23 & 15 & 11 & 8 & 6 & 4 & 3 & 3 & 2 & 2 \\
\hline 15 & 6 & 568 & 242 & 118 & 63 & 37 & 23 & 15 & 10 & 7 & 5 & 4 & 3 & 2 & 2 & 2 & 1 \\
\hline 15 & 7 & 392 & 167 & 81 & 44 & 25 & 16 & 10 & 7 & 5 & 4 & 3 & 2 & 2 & 1 & 1 & 1 \\
\hline 15 & 8 & 284 & 121 & 59 & 32 & 19 & 12 & 8 & 5 & 4 & 3 & 2 & 2 & 1 & 1 & 1 & 1 \\
\hline 15 & 9 & 215 & 92 & 45 & 24 & 14 & 9 & 6 & 4 & 3 & 2 & 2 & 1 & 1 & 1 & 1 & 1 \\
\hline 15 & 10 & 167 & 71 & 35 & 19 & 11 & 7 & 5 & 3 & 2 & 2 & 1 & 1 & 1 & 1 & 1 & 1 \\
\hline 20 & 3 & 3,046 & 1,297 & 630 & 337 & 194 & 119 & 76 & 51 & 35 & 25 & 18 & 14 & 10 & 8 & 6 & 5 \\
\hline 20 & 4 & 1,490 & 635 & 308 & 165 & 95 & 58 & 38 & 25 & 17 & 12 & 9 & 7 & 5 & 4 & 3 & 3 \\
\hline 20 & 5 & 866 & 369 & 179 & 96 & 56 & 34 & 22 & 15 & 10 & 7 & 6 & 4 & 3 & 3 & 2 & 2 \\
\hline 20 & 6 & 558 & 238 & 116 & 62 & 36 & 22 & 14 & 10 & 7 & 5 & 4 & 3 & 2 & 2 & 2 & 1 \\
\hline 20 & 7 & 386 & 165 & 80 & 43 & 25 & 15 & 10 & 7 & 5 & 4 & 3 & 2 & 2 & 1 & 1 & 1 \\
\hline 20 & 8 & 281 & 120 & 58 & 32 & 18 & 11 & 7 & 5 & 4 & 3 & 2 & 2 & 1 & 1 & 1 & 1 \\
\hline 20 & 9 & 212 & 91 & 44 & 24 & 14 & 9 & 6 & 4 & 3 & 2 & 2 & 1 & 1 & 1 & 1 & 1 \\
\hline 20 & 10 & 165 & 71 & 35 & 19 & 11 & 7 & 5 & 3 & 2 & 2 & 1 & 1 & 1 & 1 & 1 & 1 \\
\hline
\end{tabular}

In practice, the information available in this study enable these investigations to 512 scenarios formed by combinations of $i$ treatments, r repetitions, and $\mathrm{d}$ differences between treatment means to be detected as significant at the $5 \%$ probability (Table 2 ). Alternatively, other scenarios may be simulated by the expression $\left\{2\left(t_{1}+t_{2}\right)^{2} C V^{2} / r d^{2}\right\}$
(Hatheway, 1961) based on the estimated index b $=0.4269$ of soil heterogeneity of Smith (1938) (Figure 2) and the coefficient of variation ( $C V=23.60 \%$ ) between the 144 BEU (Table 1). For example, in order to evaluate the FM in eight treatments with four repetitions and $d=25 \%$, in a randomized block design (RBD), the parameters are: $b=0.4269$; 
$\mathrm{DF}=(8-1)(4-1)=21 ; \quad \mathrm{t}_{1}=\operatorname{INVT}(0.05 ; 21)=2.07961383 ;$ $\mathrm{t}_{2}=\operatorname{INVT}(0.40 ; 21)=0.85907403 ; \quad \mathrm{CV}=23.60 \%$; $r=4 ; d=25 \%$. Thus, optimum plot size $(X o)$ is: $X_{0}=\sqrt[0.426]{2\left(2.07961383+0.85907403^{2} 23.60^{2} / 4 \times 25^{2}\right.}=23.49 \cong 24 \mathrm{BEU}$. Further, in scenario simulations with completely randomized design (CRD), only the expression for calculating the degrees of freedom changes, that is, for this design, $D F=i(r-1)$, where $i$ is the number of treatments and $r$ is the number of repetitions. Thus, for this example, the parameters are: $b=0.4269$; $\mathrm{DF}=(8)(4-1)=24 ; \quad \mathrm{t}_{1}=\operatorname{INVT}(0.05 ; 24)=2.06389854$; $\mathrm{t}_{2}=\mathrm{NVT}(0.40 ; 24)=0.85685545 ; \mathrm{CV}=23.60 \% ; \mathrm{r}=4 ; \mathrm{d}=25 \%$. Thus, $X_{0}=\sqrt[0.426]{2\left(2.06389854+0.85685544^{2} 23.60^{2} / 4 \times 25^{2}\right.}=22.82 \cong 23 \mathrm{BEU}$. For the same experimental conditions, the smaller plot size in CRD (BEU 23) related to RBD (24 BEU) confirms its higher efficiency when the experimental area is homogeneous (Storck et al., 2011).

The researcher can take advantage of the information provided in the study to define the plot size and the number of repetition concerning flax experiments. Furthermore, other scenarios not presented in this study can be simulated.

\section{Conclusions}

In experiments planned on randomized block design, with 5 to 20 treatments and four repetitions, plots with $7 \mathrm{~m}^{2}$ are sufficient to identify significant differences between treatments regarding fresh matter of aerial part in flax, at $5 \%$ probability, of $34 \%$ of the experiment overall mean.

\section{Acknowledgements}

To the Brazilian National Council for Scientific and Technological Development (CNPq - Processes 401045/2016-1 e 304652/2017-2), the Coordination for the Improvement of Higher Level Personnel (CAPES), and the Rio Grande do Sul Research Foundation (FAPERGS) for granting scholarships to the authors.

\section{References}

Alves, S.M.F., Seraphin, J.C. 2004. Soil heterogeneity coefficient and plot size. Pesquisa Agropecuária Brasileira 39: 105-111.

Brum, B., Lopes, S.J., Storck, L., Santos, V.J., Benz, V., Lovato, C. 2008. Optimal plot size for experiments whit grains sorghum in two times of sowing. Ciência Rural 38: 315-320.

Cargnelutti Filho, A., Toebe, M., Alves, B.M., Burin, C., Neu, I.M.M., Facco, G. 2014a. Plot size to evaluate the mass of plants of velvet bean. Comunicata Scientiae 5: 196-204.
Cargnelutti Filho, A., Toebe, M., Burin, C., Casarotto, G., Alves, B.M. 2014b. Experimental designs in turnip sown to haul and in line. Bioscience Journal 30: 677686.

Cherubin, M.R., Fabris, C., Weirich, S.W., Rocha, E.M.T., Basso, C.J., Santi, A.L., Lamego, F.P. 2014. Agronomic performance of maize in succession to cover crop species under no-tillage system in southern Brazil. Global Science and Technology 7: 76-85.

Cocco, C., Boligon, A.A., Andriolo, J.L., Oliveira, C.S., Lorentz, L.H. 2009. Plot size and shape in trials using strawberry cultivated with soil or using hydroponics. Pesquisa Agropecuária Brasileira 44: 681-686.

Donato, S.L.R., Siqueira, D.L., Silva, S.O., Cecon, P.R., Silva, J.A., Salomão, L.C.C. 2008. Estimates of plot size for the evaluation of phenotipics descriptors in banana. Pesquisa Agropecuária Brasileira 43: 957-969.

Feijó, S., Storck, L., Lúcio, A.D., Lopes, S.J., Garcia, D.C., Carpes, R.H. 2008. Heterogeneity index of zucchini yield on a protected environment and experimental planning. Horticultura Brasileira 26: 35-39.

Floss, E.L. 1983. Linho, cultivo e utilização. Passo Fundo: UPF, 40p. (Boletim Técnico, 3).

Hatheway, W.H. 1961. Convenient plot size. Agronomy Journal 53: 279-280.

Heldwein, A.B., Buriol, G.A., Streck, N.A. 2009. O clima de Santa Maria. Ciência e Ambiente 38: 43-58.

Henriques Neto, D., Sediyama, T., Souza, M.A., Cecon, P.R., Yamanaka, C.H., Sediyama, M.A.N., Viana, A.E.S. 2004. Plot size in experiments with wheat irrigated under no-tillage and conventional tillage. Pesquisa Agropecuária Brasileira 39: 517-524.

Lorentz, L.H., Boligon, A.A., Storck, L., Lúcio, A.D. 2010. Plot size and experimental precision for sunflower production. Scientia Agricola 67: 408-413.

Lorentz, L.H., Lúcio, A.D. 2009. Plot size and shape for chili pepper in plastic greenhouse. Ciência Rural 39: 2380-2387.

Lorentz, L.H., Martin, T.N., Boligon, A.A., Storck, L., Lúcio, A.D., Lopes, S.J. 2007. Plot size and experimental precision in wheat trials in no-tillage system. Científica 35: 129-135.

Lúcio, A.D., Haesbaert, F.M., Santos, D., Benz, V. 2011. Estimate of plot size for experiments with lettuce. Horticultura Brasileira 29: 510-515.

Lúcio, A.D., Haesbaert, F.M., Santos, D., Schwertner, D.V., Brunes, R.R. 2012. Sample size and plot size for 
growth and productivity characteristics of tomato. Horticultura Brasileira 30: 660-668.

Mayor-Durán, V.M., Blair, M., Muñoz, J.E. 2012. Metodología para estimar el coeficiente de heterogeneidad del suelo, el número de repeticiones y el tamaño de parcela en investigaciones con frijol (Phaseolus vulgaris L.). Acta Agronómica 61: 32-39.

Novello, D., Pollonio, M.A.R. 2011 . Characterization and properties of linseed (Linum usitatissimun L.) and by-products. Boletim do Centro de Pesquisa de Processamento de Alimentos 29: 317-330.

Rigon, J.P.G., Baronio, C.A., Zwirtes, A.L., Capuani, S. 2011. Succession of cover crops on yield components of bean. Revista Verde 6: 196-203.

Santos, D., Haesbaert, F.M., Lúcio, A.D., Storck, L., Cargnelutti Filho, A. 2012. Plot size for the green beans crop. Revista Ciência Agronômica 43: 119128.

Smith, H.F. 1938. An empirical law describing heterogeneity in the yields of agricultural crops. Journal of Agricultural Science 28: 1-23.

Storck, L., Garcia, D.C., Lopes, S.J., Estefanel, V. 2011 . Experimentação vegetal. 3.ed. UFSM, Santa Maria, Brasil. 200 p.

Viana, A.E.S., Sediyama. T., Lopes, S.C., Cecon, P.R., Silva, A.A. 2003. Estudos sobre tamanho de parcela em experimentos com mandioca (Manihot esculenta Crantz). Acta Scientiarum. Agronomy 25: 281-289. 